\title{
BMJ Open A/C study protocol: a cross-sectional study of HIV epidemiology among African, Caribbean and Black people in Ontario
}

\author{
Lawrence Mbuagbaw (10 , ${ }^{1}$ Wangari Tharao, ${ }^{2}$ Winston Husbands, ${ }^{3}$ Laron E Nelson, ${ }^{4}$ \\ Muna Aden, ${ }^{2}$ Keresa Arnold, ${ }^{5}$ Shamara Baidoobonso, ${ }^{5}$ Charles Dabone, ${ }^{6}$ \\ OmiSoore Dryden, ${ }^{7}$ Egbe Etowa, ${ }^{6}$ Jemila Hamid, ${ }^{8}$ Fatimah Jackson-Best, ${ }^{9}$ \\ Bagnini Kohoun, ${ }^{6}$ Daeria O Lawson (D) , ${ }^{1}$ Aisha K Lofters, ${ }^{10}$ Henry Luyombya, ${ }^{3}$ \\ Tola Mbulaheni, ${ }^{11}$ Paul Mkandawire, ${ }^{12}$ Mary Ndungu, ${ }^{13}$ Agatha Nyambi, ${ }^{3}$ \\ Suzanne Obiorah, ${ }^{14}$ Fanta Ongoiba, ${ }^{13}$ Clémence Ongolo-Zogo, ${ }^{1}$ Chinedu Oraka, ${ }^{15}$ \\ Rita Shahin, ${ }^{16}$ Sanni Yaya, ${ }^{17}$ Andrew Hendricks, ${ }^{15}$ Akalewold Gebremeskel, ${ }^{6}$ \\ Haoua Inoua, ${ }^{18}$ Josephine Etowa ${ }^{6}$
}

To cite: Mbuagbaw L, Tharao W, Husbands W, et al. A/C study protocol: a cross-sectional study of HIV epidemiology among African, Caribbean and Black people in Ontario. BMJ Open 2020;10:e036259. doi:10.1136/ bmjopen-2019-036259

- Prepublication history and additional material for this paper are available online. To view these files, please visit the journal online (http://dx.doi. org/10.1136/bmjopen-2019036259).

Received 12 December 2019 Revised 13 April 2020 Accepted 08 June 2020

Check for updates

(c) Author(s) (or their employer(s)) 2020. Re-use permitted under CC BY-NC. No commercial re-use. See rights and permissions. Published by BMJ.

For numbered affiliations see end of article.

Correspondence to Dr Lawrence Mbuagbaw; mbuagblc@mcmaster.ca

\section{ABSTRACT}

Introduction African, Caribbean and Black (ACB) communities are disproportionately infected by HIV in Ontario, Canada. They constitute only $5 \%$ of the population of Ontario yet account for $25 \%$ of new diagnoses of HIV. The aim of this study is to understand underlying factors that augment the HIV risk in ACB communities and to inform policy and practice in Ontario.

Methods and analysis We will conduct a crosssectional study of first-generation and second-generation ACB adults aged 15-64 in Toronto $(n=1000)$ and Ottawa $(n=500)$ and collect data on sociodemographic information, sexual behaviours, substance use, blood donation, access and use of health services and HIVrelated care. We will use dried blood spot testing to determine the incidence and prevalence of HIV infection among ACB people, and link participant data to administrative databases to investigate health service access and use. Factors associated with key outcomes (HIV infection, testing behaviours, knowledge about HIV transmission and acquisition, HIV vulnerability, access and use of health services) will be evaluated using generalised linear mixed models, adjusted for relevant covariates. Ethics and dissemination This study has been reviewed and approved by the following Research Ethics Boards: Toronto Public Health, Ottawa Public Health, Laurentian University; the University of Ottawa and the University of Toronto. Our findings will be disseminated as community reports, fact sheets, digital stories, oral and poster presentations, peer-reviewed manuscripts and social media.

\section{BACKGROUND}

African, Caribbean and Black (ACB) communities, including people from sub-Saharan African and Caribbean countries, constitute one of six priority populations in Ontario, Canada who have a greater vulnerability to
Strengths and limitations of this study

This study will address issues affecting the vulnerability of African, Caribbean and Black people to HIV in Ontario, Canada using robust community-based research approaches.

- We will link our data to administrative databases allowing us to capture information on access and use of health services and HIV-related care.

- The study will be limited to only two major metropolitan centres in Ontario, Canada.

HIV due to social and systemic factors that threaten health. ${ }^{1}$ Even though ACB communities constitute only $5 \%$ of Ontario's population, in 2015 they accounted for about $25 \%$ of all new infections. ${ }^{2}$

Existing provincial HIV surveillance data does not always have information on race or ethnicity, ${ }^{34}$ and therefore, many ACB people with HIV may be missed. These ACB populations include Ontario residents who test positive, and people with HIV who migrate to Ontario from other provinces and countries and test positive in Ontario for the first time. Furthermore, provincial surveillance does not always capture detailed information on factors associated with HIV acquisition and transmission (such as sexual risk behaviours and substance use) or the broader determinants of health that may increase vulnerability to HIV among ACB people in Canada. In 2016 and 2017, data on race/ethnicity and exposure category were available for only $47.4 \%$ and $49.3 \%$ of cases, respectively. ${ }^{34}$ 
Provision of comprehensive, culturally appropriate, responsive interventions is a key strategy for improving health and well-being among ACB populations in Ontario. ${ }^{1}$ Understanding lived experiences and determinants of health of ACB people-including access to health services-is essential to tackling the root causes of HIV vulnerability and providing effective and specific HIV services. ${ }^{5}$ For ACB people living with HIV, stigma and discrimination compound the documented barriers to achieving health and well-being. ${ }^{26}$

Despite these concerns, little research has been done to measure health service utilisation by ACB populations in Ontario. In a 2004-2005 survey of 456 people from East African communities in the Greater Toronto Area (GTA), $87 \%$ of participants reported having a family doctor and $86 \%$ reporting seeing their family doctor in the past year. However, 27\% reported a time in the past year when they felt they needed care and did not receive it. In addition, women, younger participants, and more recent immigrants were less likely to have a family doctor. ${ }^{7}$ Likewise, an uneven geographic distribution of service providers for ACB community members has been documented. ${ }^{2}$ Other studies have identified high rates of childhood adversity-which may be precipitated by migrant statusin ACB people living with HIV. ${ }^{8}$

Given the disparities highlighted above, the Public Health Agency of Canada (PHAC), in collaboration with provincial health departments and community-based organisations initiated the 'track' studies. The work presented below belongs to the $\mathrm{A} / \mathrm{C}$ (African/Caribbean) track and is called the 'A/C study'.

The purpose of the A/C study is to develop an understanding of underlying factors that augment the HIV risk and vulnerability of ACB communities and to inform policy and practice in Ontario, Canada with regard to HIV care for ACB people.

The primary objectives of the A/C Study are to describe the following: (1) prevalence of HIV; (2) behaviours associated with transmission of HIV; (3) testing behaviour for HIV; (4) care and treatment history for HIV; (5) core knowledge related to HIV transmission and acquisition; and (6) key individual and structural factors that affect vulnerability to HIV.

The secondary objectives of the A/C Study are to estimate the incidence of HIV and to evaluate access to and use of health services.

\section{METHODOLOGY \\ Design}

We will conduct a cross-sectional survey of ACB adults in the GTA and Ottawa, two major metropolitan centres in Ontario, Canada. The study will be implemented using the principles of community based research-a strong collaborative connection between researchers and community members to conduct research to address a community issue. ${ }^{9}$

\section{Patient and public involvement}

The research team has consulted with a range of community health centres and AIDS service organisations (ASOs) in Toronto and Ottawa in order to develop safe and culturally accessible delivery methods to members of the community and to organise the logistics of the study. Additionally, we have engaged ASO representatives in our monthly meetings to discuss all aspects of the research activities including the Black Coalition for AIDS Prevention (Black CAP), the African and Caribbean Council on HIV/AIDS in Ontario, and Africans in Partnership Against AIDS. The A/C Study is guided by the following community-driven values:

\section{Community stewardship}

ACB community members, researchers and service providers have been involved in all discussions about the study and will continue to be actively engaged in all phases and processes. The study leaders (coprincipal investigators and coinvestigators) are mainly ACB people (including persons living with HIV) with a background in health and HIV research, programme development, service provision, advocacy and community engagement. ACB people will also be involved as advisors and collaborators (eg, advising on strategy, recruitment, data management, facilitating respectful and principled outreach and engagement)

\section{Diversity}

ACB communities share commonalities, but they are not homogeneous. The A/C Study will contribute to strengthening health and well-being among ACB communities by engaging a broad range of identities and population segments. In so doing, the $\mathrm{A} / \mathrm{C}$ Study will capture and reflect their challenges and strengths to make the project and its aftermath successful. Our study team includes investigators of diverse genders, sexualities, language groups (English, French and other languages), professional affiliations, national origins and age that capture the diversity of ACB stakeholders. We will also recruit a similarly diverse sample of participants.

\section{Capacity building}

ACB communities possess resources (specifically knowledge and abilities) that can inform the work of researchers or policy-makers. The A/C Study aspires to empower the community and to increase the ability of service providers working with the communities to address HIV-related issues. The study will also support capacity building for $\mathrm{ACB}$ graduate students and postdoctoral fellows.

\section{Integrating knowledge translation and action}

The A/C Study team brings together researchers and knowledge users (service providers, people living with HIV, etc) to collaboratively develop, share and use the knowledge generated by A/C Study. The team will design and implement knowledge translation and exchange (KTE) activities with the aim of reducing HIV incidence and prevalence, developing interventions to address 
critical issues, and strengthening health and well-being among ACB people. The knowledge generated by A/C Study will be disseminated to meet the needs of diverse stakeholders, while upholding and respecting the dignity of ACB people.

The ACB researchers and community partners in Ontario have a long standing history of collaboration in research, but particularly with the regularly held 'ACB Think Tanks'-workshops used to set research priorities and conduct community-based research on issues such as HIV-related stigma, the needs of ACB women living with HIV and gay and bisexual ACB men.

\section{Eligibility}

Potential participants must meet the following inclusion criteria to participate in A/C Study: born in a Caribbean or sub-Saharan African country, or born elsewhere (including Canada) with a parent born in one of those countries; aged 15-64 years old at the time of survey; residence in the GTA or Ottawa; capacity to communicate in English or French; and capable of providing informed consent.

\section{Sampling}

Our sample size is based on a range of values of the estimated prevalence of HIV among first-generation and second-generation ACB people, the distribution of ACB populations from the Caribbean (58\%) and Africa (42\%), derived from the 2016 National Household Survey ${ }^{10}$ and the proportions of ACB people in the GTA and Ottawa. ${ }^{11}$ Using quota samples that reflect these distributions and an HIV prevalence of $2 \%$, applying the Wilson CI approach with continuity correction, ${ }^{12}$ we derived a sample size of 1500 (1000 in the GTA; and 500 in Ottawa. This sample reflects the current proportions of $\mathrm{ACB}$ populations in Toronto $(7.5 \%)$ and Ottawa $(6.3 \%){ }^{13}$

\section{Setting}

Participants will be screened and recruited through social networks (Black Toronto Community Support and Racial Healthy Equity Network on Facebook), events (Afrofest, the Toronto Caribbean Festival, Pride, Blockrama, the Villagefest, The Black Owned Summer and Winter markets) and venues populated by ACB people (TAIBU and Black Creek Community Health Centres, La Passerelle, etc).

\section{Recruitment}

We plan to recruit 1000 participants in the GTA and 500 participants in Ottawa using a peer recruitment strategy. Survey venues that are frequented by $\mathrm{ACB}$ people will be selected with input from local team members and collaborators. This form of recruitment should generate a sample that is similar in age, gender, and country of birth to Statistics Canada data pertaining to the GTA and Ottawa. These approaches have been used in previous studies to limit selection bias and create representative samples. ${ }^{14}$ In the GTA and Ottawa, we will recruit and train a diverse cadre of 25 and 17 peer recruiters, respectively, who are broadly representative of the target population (including people living with HIV). Trained peer recruiters will approach potentially eligible ACB people through their social networks and at various venues and events. Participants who are interested in participating will be given a card that is stamped with the recruiter's unique code then referred to the study coordinator. Participants who contact the coordinator will be asked for the code and will be scheduled for an interview with a study interviewer. Codes on the recruitment cards will also be used to track where, when and how participants were recruited to enhance our efforts to track and monitor patterns of recruitment.

\section{Data collection}

\section{Consent}

Written consent will be obtained using two information and consent forms. The first form, for the A/C Study survey and dry blood spot (DBS), will invite potential participants to take part in the study and provide them with information on the purpose of the A/C Study and what it entails. Participants will be allowed to complete the survey even if they do not consent to the DBS but will not be eligible for the DBS without taking the survey. The second form, for the administrative data linkage, will provide the same information but will ask participants to consent to the data linkage portion of the study. To mitigate potential concerns participants might have about data linkage, the second form will provide ways in which the linked data will be used, and the restrictions on its use. Consent will be obtained using the first form prior to administering the survey, and again with the second form after the survey and DBS portion has concluded but before data collection for the data linkage is initiated. At both points, participants will be informed that they can withdraw consent at any point during the process.

\section{Survey}

The A/C Study survey consists of a questionnaire available in French and English spanning multiple domains, including sociodemographic information; sexual behaviour; substance use; blood donation; access to and use of health systems and services; and HIV testing, care and treatment. The questionnaire items include a mix of questions that have been used in similar studies with other population groups across Canada, and questions generated by the study team. ${ }^{715}$ Self-administered or interviewer-assisted questionnaire on tablets or laptops will be used. Responses to questions on the respective variables will be used to categorise HIV vulnerability as high or low; ascertain knowledge about HIV and determine access to and use of services as adequate or inadequate.

\section{Specimen collection and laboratory testing}

A DBS will be requested from each participant, but participants are free to refuse and remain in the survey. Participants who indicate that they want to have a DBS test will be tested by peers who were trained under guidelines 
developed by the provincial Ministry of Health, and according to a training programme approved by the Ministry. This training includes infection control, DBS collection and exposure to blood protocols. The specimen will be tested by PHAC for antibodies against HIV. Test results will be linked to behavioural data for the purpose of analysis, while preserving anonymity. HIV screening will be performed using the Bio-Rad GS HIV Combo $\mathrm{Ag} / \mathrm{Ab}$ assay. Confirmatory testing will subsequently be performed using the AVIOQ HIV-1 Microelisa System.

HIV-positive specimens will be tested using the detuned (or other similar) assay designed to differentiate recent infections from older, established infections. Detuned assays are used for surveillance purposes only, to identify HIV infections where persons have seroconverted within the last 6 months. This assay functions by identifying differences between high antibody titers in specimens from individuals with long-term infection and lower titres from individuals who were recently infected (approximately $<6$ months from time of specimen collection). No genetic testing of human genomic material will be performed on any survey specimens. Specimens will be destroyed immediately after testing. Laboratory test results will be entered into a password-protected surveillance database and linked to data for the corresponding participant via the study ID code. Daily, we will check a random selection of DBS to ascertain whether samples are being correctly captured; and communicate with the lab and PHAC at regular intervals to identify any problems with the DBS samples.

\section{Compensation}

The honorarium for each study participant will be \$C40. This honorarium matches honoraria offered in similar research projects in this population. ${ }^{715}$ It also aims to compensate participants for the amount of time anticipated to complete the questionnaire and DBS. In addition to receiving an honorarium, each participant will be offered a voluntary point-of-care HIV test funded by the study team, the Ontario HIV Treatment Network (OHTN) and the AIDS Bureau, Ontario Ministry of Health and Long Term.

\section{Administrative data linkage}

To examine questions of health service access and utilisation, an increasing number of research studies in Ontario are including an option for participants to consent to provide their personal information that is, Ontario Health Insurance Plan numbers that can be linked to the administrative data at the Institute for Clinical Evaluative Science (ICES; https://www.ices.on.ca/). ICES is an independent non-profit organisation whose infrastructure funding and access to Ontario's large administrative databases is provided by the Ontario Ministry of Health and LongTerm Care. ICES has a special designation to compile and analyse data about the management and effectiveness of healthcare under Ontario's Personal Health Information
Protection Act-this designation, granted by the Information and Privacy Commissioner of Ontario (IPC) is subject to ongoing IPC oversight and renewal every 3 years. ICES houses deidentified data on health system utilisation and undertakes research on a wide variety of healthcare issues. Administrative data housed by ICES includes hospitalisations and emergency room visits; Immigration, Refugee and Citizenship Canada data; data from continuing care and ambulatory care centres; the Ontario Drug Benefit programme and physicians' billing claims. Collecting consent to link to ICES data has been successfully incorporated into other research studies involving populations affected by HIV (eg, Ontario HIV Treatment Network Cohort Study, ${ }^{16}$ and the Canadian HIV Women's Sexual and Reproductive Health Cohort Study ${ }^{17}$ ). We will ask A/C Study participants for consent to provide personal information for data linkage to ICES. Participants who consent to the ICES data linkage component will give the interviewer their personal identifying information and health card number necessary to link A/C Study data to ICES data. Several steps will be taken to ensure participant confidentiality and data security. Full details on the encryption processes are provided in the online supplementary file. The recruitment and data collection procedures are outlined in figure 1.

\section{Analysis and interpretation}

We will use descriptive statistics to characterise the cohort of ACB people who participate in the A/C Study. Continuous data (eg, age) will be described using means and SD or medians (quartile 1; quartile 3). Categorical data (eg, gender, place of residence) will be described using counts and percentages.

The prevalence of HIV will be estimated as the proportion of people with a positive HIV test expressed as a percentage with $95 \%$ CIs. The incidence of HIV will be estimated at the proportion of people with a positive HIV test determined to have occurred within the last 6 months, expressed as a percentage with $95 \%$ CI. The prevalence and incidence of HIV will be summarised by age group, residence, ethno-racial identity, income, sex, gender and other sociodemographic variables.

The factors associated with key outcomes (HIV infection (binary), testing behaviours (binary), knowledge about HIV transmission and acquisition (binary), HIV vulnerability (binary), access and use of health services (binary)) will be evaluated using generalised linear mixed models, adjusted for relevant covariates. Covariates will be entered into the model as blocks composed of categories such as sociodemographics, sexual behaviours, substance use. The link function will be specified according to the nature of the outcome (eg, the logit link for binary outcomes). Subgroups will be explored using interaction term (exposure * subgroup) p values. Model fit will be assessed using the Akaike information criterion (AIC) by comparing full models to partial models, where the model with the lower AIC will be preferred. ${ }^{18}$ ORs and 95\% CIs will be reported. The type 1 error rate will be 


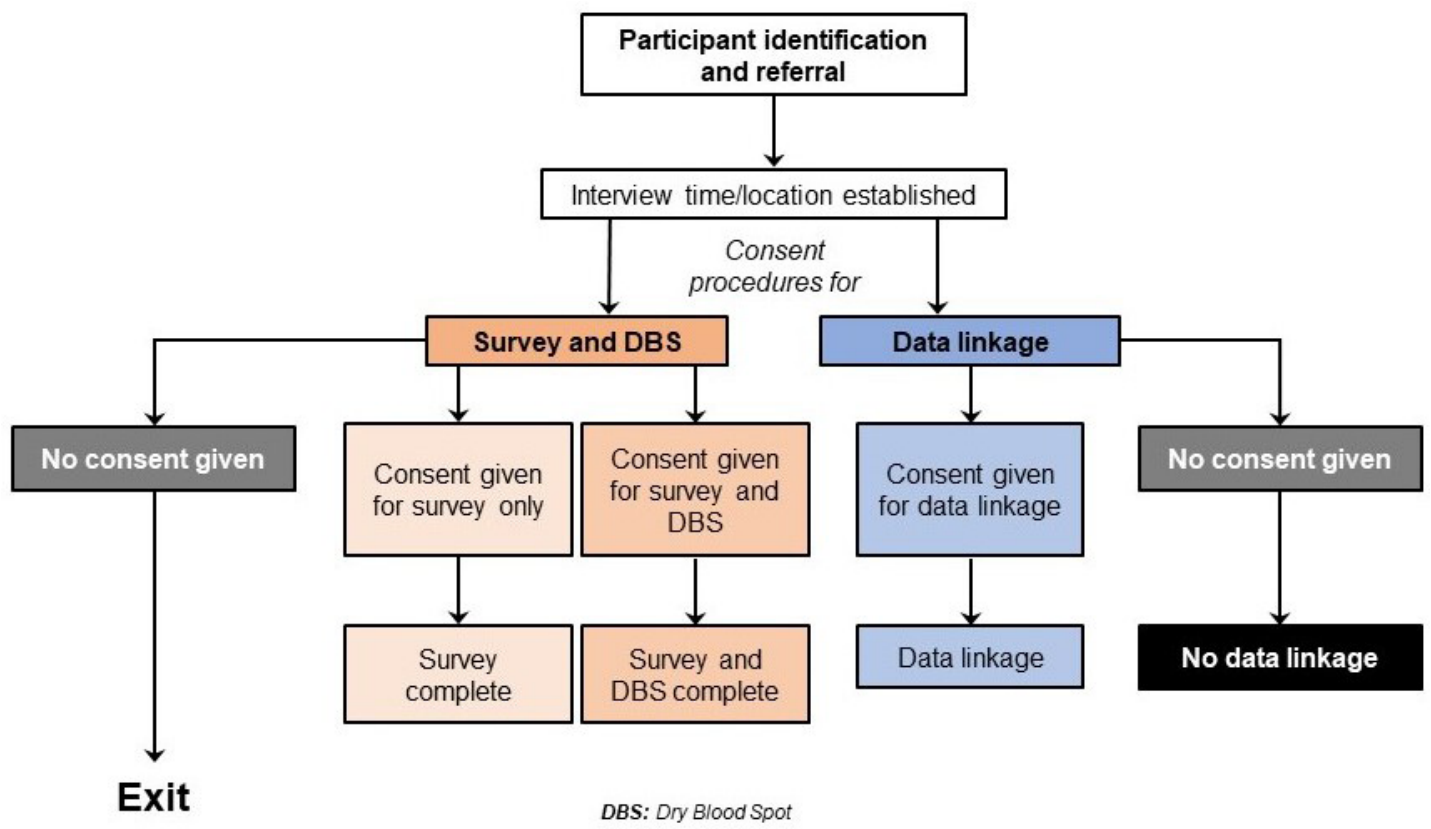

Figure 1 Outline of recruitment and data collection procedures. DBS, dry blood spot.

set at 5\%. Data will be analysed using IBM SPSS V.25.0 (SPSS).

In addition to the formal statistical techniques outlined above, these findings will be analysed and interpreted in the light of the lived experiences of ACB communities and available literature. As part of our KTE strategy, community members will participate in deliberations to enhance our understanding of the results and validate our findings to ensure that they are truly representative of their experiences. This approach is distinct from non-community-based research and reflects meaningful engagement of the community such that our methodology, analyses and interpretation reflect the experiences and understanding of ACB people. The planned analyses are outlined in table 1.

\section{Additional studies}

\section{Sex-based and gender-based analysis}

In order to investigate sex and gender issues, we will: (1) investigate any differences in female representativeness using a two-tailed z-test of the null hypothesis that the proportion of women within our dataset is equal to the proportion of women with HIV in the general population (alpha $=0.05)$; (2) stratify our outcomes by sex and gender, which will illustrate differences in outcomes based on sex and gender and will inform subsequent analyses; and (3) test the interaction between outcomes and sex or gender.

\section{Healthcare issues among francophone ACB people}

Francophone ACB people in Ontario represent a unique minority group due to their ethnic differences and language barriers. We will conduct a substudy on participants who identify as Francophone in order to identify health issues that may be contextual to this group.

\section{Blood donation}

This study will provide an opportunity to explore how often and why ACB people donate blood, and if they experience challenges with donating blood.

\section{DISCUSSION}

Adequately addressing the HIV epidemic by ensuring that people of all sociodemographic backgrounds have access to information, preventive services and treatment is of benefit to the entire country. Even though ACB populations represent only $2.5 \%$ of the Canadian population, $16 \%$ of the people living with HIV are ACB. ${ }^{19}$ In Ontario, ACB communities constitute only 5\% of Ontario's population, but account for up to $25 \%$ of all new infections. ${ }^{4}$ As such they are an important pocket of disproportionate HIV disease burden for which concerted efforts are needed to curb the spread of the HIV in Ontario and Canada. Given that 52\% of Canada's ACB population (over half a million people) lives in Ontario, ${ }^{13}$ any investigations geared towards understanding their accrued vulnerability will benefit the whole country. Our findings will have impact on other Canadian communities by: (1) helping to build capacity for future ethno-racial studies with visible minority communities across the country, which furthers both our provincial and federal aims to address health inequities; and (2) our findings may yield societal benefits by leading to better HIV care and reduced costs of care by identifying barriers to optimal access to care.

This study will be the largest cross-sectional investigation of issues that affect ACB vulnerability to HIV in Canada, using both survey-based and administrative data. This ACB-led study will directly address current ACB 
Table 1 Outline of statistical plan

$\begin{array}{lllll}\text { Objectives Outcomes } & \text { Outcome measure } & \text { Covariates }\end{array}$

Primary objective

What is the

prevalence of HIV?

HIV infection (yes/no) Self-reported HIV

positive status or a

positive HIV test result

*Sociodemographic

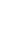

\begin{tabular}{|c|c|c|c|c|}
\hline & & & & covariate \\
\hline $\begin{array}{l}\text { What behaviours are } \\
\text { associated with HIV } \\
\text { transmission? }\end{array}$ & HIV infection (yes/no) & $\begin{array}{l}\text { Self-reported HIV } \\
\text { positive status or a } \\
\text { positive HIV test result }\end{array}$ & $\begin{array}{l}\text { *Sociodemographic } \\
\text { †Sexual behavioural } \\
\text { †Substance use }\end{array}$ & $\begin{array}{l}\text { GLMM with binary } \\
\text { logistic distribution }\end{array}$ \\
\hline $\begin{array}{l}\text { What factors are } \\
\text { associated with } \\
\text { testing behaviours for } \\
\text { HIV? }\end{array}$ & $\begin{array}{l}\text { HIV testing ever done } \\
\text { (yes/no) } \\
\text { HIV testing done in } \\
\text { past } 6 \text { months (yes/no) }\end{array}$ & $\begin{array}{l}\text { Self-reported response } \\
\text { to HIV testing }\end{array}$ & $\begin{array}{l}\text { *Sociodemographic } \\
\dagger \text { Sexual behavioural } \\
\text { † Substance use } \\
\S \text { Access and use of health } \\
\text { services } \\
\text { १HIV-related healthcare }\end{array}$ & $\begin{array}{l}\text { GLMM with binary } \\
\text { logistic distribution }\end{array}$ \\
\hline $\begin{array}{l}\text { What are the levels of } \\
\text { knowledge regarding } \\
\text { HIV transmission and } \\
\text { acquisition? }\end{array}$ & $\begin{array}{l}\text { HIV knowledge } \\
\text { (adequate/ inadequate) }\end{array}$ & $\begin{array}{l}\text { Self-reported responses } \\
\text { to HIV knowledge } \\
\text { questions }\end{array}$ & *Sociodemographic & $\begin{array}{l}\text { Descriptive statistics: } \\
\mathrm{n}(\%) 95 \% \mathrm{Cl} \text { or } \\
\text { mean (SD) or median } \\
\text { (IQR) per categorical } \\
\text { covariate }\end{array}$ \\
\hline $\begin{array}{l}\text { What are the key } \\
\text { individual and } \\
\text { structural factors that } \\
\text { affect vulnerability to } \\
\text { HIV? }\end{array}$ & $\begin{array}{l}\text { HIV vulnerability** } \\
\text { (high/low) }\end{array}$ & $\begin{array}{l}\text { Combination of } \\
\text { knowledge and } \\
\text { behavioural practices } \\
\text { indicative of high } \\
\text { vulnerability }\end{array}$ & $\begin{array}{l}\text { *Sociodemographic } \\
\text { † Sexual behavioural } \\
\text { ¥ Substance use } \\
\S \text { Access and use of health } \\
\text { services } \\
\text { ๆHIV-related healthcare }\end{array}$ & $\begin{array}{l}\text { GLMM with binary } \\
\text { logistic distribution }\end{array}$ \\
\hline \multicolumn{5}{|l|}{ Secondary Objectives } \\
\hline $\begin{array}{l}\text { What is the incidence } \\
\text { of HIV? }\end{array}$ & $\begin{array}{l}\text { HIV infection within the } \\
\text { last } 6 \text { months (yes/no) }\end{array}$ & $\begin{array}{l}\text { A positive HIV test result } \\
\text { with infection within the } \\
\text { last } 6 \text { months, using } \\
\text { detuned assays }\end{array}$ & *Sociodemographic & $\begin{array}{l}\text { Descriptive statistics: } \\
\text { n (\%) 95\% Cl or mean } \\
\text { (SD) or median (IQR per } \\
\text { categorical covariate }\end{array}$ \\
\hline $\begin{array}{l}\text { What are the levels of } \\
\text { access to and use of } \\
\text { health services? }\end{array}$ & $\begin{array}{l}\text { Access and use of } \\
\text { health services } \\
\text { (adequate/ inadequate) }\end{array}$ & $\begin{array}{l}\text { Self-reported responses } \\
\text { to access and use of } \\
\text { health services } \\
\text { Resources use metrics } \\
\text { from administrative } \\
\text { databases }\end{array}$ & *Sociodemographic & $\begin{array}{l}\text { Descriptive statistics: } \\
\mathrm{n}(\%) \text { 95\% Cl or mean } \\
\text { (SD) or median (IQR per } \\
\text { categorical covariate }\end{array}$ \\
\hline
\end{tabular}

*Sociodemographic: age group (ordinal), residence (categorical), ethno-racial identity (categorical), income (categorical), gender/sex (categorical), migration (categorical), marital status (categorical), education (ordinal), religion (categorical), employment (categorical), housing (ordinal).

†Sexual behavioural: age at first intercourse (continuous), sexual orientation (categorical), sexual practices (categorical), number of partners (count), condom use (ordinal), partners HIV status (categorical), transactional sex (categorical), substance use and sex (categorical), genital cutting (categorical).

$\ddagger$ Substance use: injection drug use (categorical) and other substances (categorical).

$\S A c c e s s$ and use of health services: self-rated health (ordinal), primary care provider (categorical), service use (categorical), difficulties in access (categorical), sources of health information (ordinal), condom procurement (categorical), immunisation (categorical), sexually transmitted infection testing (categorical).

१HIV-related healthcare: ever tested (categorical), self-reported status (categorical), access to care (ordinal), access to medication (ordinal), alternative medicines (categorical), HIV testing practices (ordinal), HIV knowledge (ordinal).

${ }^{\star *}$ Outcome measures will be categorised after deliberation with $A / C$ study investigators.

A/C, African/Caribbean; GLMM, generalised linear mixed models; $n$, sample size.

concerns and shed light on key points in the prevention and care cascade where interventions can be developed to reduce risk, prevent infection and improve outcomes in ACB people living with HIV. The findings from this work could inform policy on how to provide equitable health services for ACB minorities. This study could also lead to: improved interventions that are grounded in accurate information, improved access to services and reduction in HIV acquisition; better estimates of prevalence and the magnitude of HIV burden among ACB 
communities; strong evidence for and assessment of risk and vulnerability for the population as a whole; substantively strengthened knowledge/evidence base to inform programmes, policy and advocacy; a better understanding of health and its determinants among ACB populations; the development of an ACB health strategy in Ontario; enhanced understanding of the engagement and prevention cascade among ACB communities, and whether or how AIDS could be ended by $2030^{20}$; increased capacity to develop, mobilise and use research evidence among ACB communities.

\section{ETHICS AND DISSEMINATION}

The A/C Study is designed with due consideration of the conventional ethical standards within the context of community realities and expectations. In addition to collective experience in conducting high-quality community-based research, ${ }^{14} 15$ the research team has made concerted efforts to address important issues related to participant compensation, managing multiple roles (eg, as researcher, recruiter, community member), informed consent, confidentiality, adequate support for peer recruiters and strategies to address sensitive, illegal or stigmatising topics including, but not limited to in-depth training offered to recruiters.

The inclusion of youth aged 15 and above was done with due consideration of their unique experiences and the factors that shape these experiences, which are difference from adults'. ${ }^{22}$ As a high-risk group for $\mathrm{HIV}^{23}$ it would be unethical to exclude them from this study or to require parental consent. Parental consent was deemed unnecessary given the anonymous nature of the A/C Study survey, and inconsistent with the principles of justice and inclusiveness. Parental consent may serve to silence young people who most need to have a voice in sexual health research. ${ }^{24}$ Further, the consent forms are accompanied by information letters written in plain, youth-friendly language that explains the purpose of both components of the study and articulates participants' rights as they relate to the voluntary nature of study participation, confidentiality, anonymity and privacy. They will also be given a list of local resources for youth.

The A/C Study is led by ACB researchers, thus following the principles of autonomy and self determination in community-led research.

The A/C Study has been approved by the following Research Ethics Boards: Toronto Public Health Research Ethics Board (TPH REB, 18 June 2018); Ottawa Public Health Research Ethics Board (OPH REB; 3 April 2018); Laurentian University Research Ethics Board (LU REB; 17 November 2017); University of Ottawa Research Ethics Board (1 September 2018), University of Toronto (25 June 2018).

Our findings will be disseminated in a comprehensive dissemination strategy that prioritises community. We will share our findings using community reports, fact sheets and digitals stories.
We will host a 3-day workshop in Toronto, convening KTE Ambassadors from some of the research sites and a digital storytelling facilitator to produce these digital stories. Digital storytelling is an innovative communitybased participatory research method that increases community members' participation in research on local health issues. ${ }^{25}$ Digital stories are 3-5 min visual narratives that synthesise images, video, audio recordings of voice and music, and text to create compelling accounts of experience. ${ }^{25}$ Through the workshop process, digital storytelling offers participants an opportunity to clarify personal, community, ethnic and cultural identity and meaning and supports and engages the community in research processes. ${ }^{26}$ We will develop and deliver poster and oral presentations at community events and relevant academic conferences. We will publish reports in peerreviewed manuscripts and create electronic content. We will also produce policy briefs targeting decision-makers including the PHAC and OHTN.

At the end of the study, the research team will package the intervention content, materials, evaluation activities and lessons learnt onto a thumb drive that will be distributed to interested stakeholders. This package may also be made available on relevant websites. We will also draft policy briefs and position statements geared towards decision makers. Our findings will also be shared on Twitter, Facebook, YouTube and Vimeo.

\section{Author affiliations}

${ }^{1}$ Department of Health Research Methods, Evidence and Impact, McMaster University, Hamilton, Ontario, Canada

${ }^{2}$ Women's Health in Women's Hands Community Health Centre, Toronto, Ontario, Canada

${ }^{3}$ Ontario HIV Treatment Network, Toronto, Ontario, Canada

${ }^{4}$ School of Nursing, Yale University, West Haven, Connecticut, USA

${ }^{5}$ African and Caribbean Council on HIV/AIDS in Ontario, Toronto, Ontario, Canada

${ }^{6}$ Faculty of Health Sciences, University of Ottawa, Ottawa, Ontario, Canada

${ }^{7}$ Faculty of Medicine, Dalhousie University, Halifax, Nova Scotia, Canada

${ }^{8}$ Children's Hospital of Eastern Ontario Research Institute, Ottawa, Ontario, Canada

${ }^{9}$ Black Health Alliance, Toronto, Ontario, Canada

${ }^{10}$ St Michael's Hospital Centre for Urban Health Solutions, Toronto, Ontario, Canada

${ }^{11}$ Dalla Lana School of Public Health, University of Toronto, Toronto, Ontario, Canada

${ }^{12}$ Carleton University, Ottawa, Ontario, Canada

${ }^{13}$ Africans in Partnership, Toronto, Ontario, Canada

${ }^{14}$ Somerset West Community Health Centre, Ottawa, Ontario, Canada

${ }^{15}$ Ottawa Public Health, Ottawa, Ontario, Canada

${ }^{16}$ Toronto Public Health, Toronto, Ontario, Canada

${ }^{17}$ Faculty of Social Sciences, University of Ottawa, Ottawa, Ontario, Canada

${ }^{18}$ AIDS Commitee of Ottawa, Ottawa, Ontario, Canada

Correction notice This article has been corrected since it was published. The author name has been updated as Akalewold Gebremeskel.

Twitter Chinedu Oraka @TheChineduOraka

Acknowledgements We acknowledge the support of the Public Health Agency of Canada's National Microbiology Laboratory (PHAC-NML) for the testing of the dried blood spots; the community members, interviewers, study coordinators and participants who are contributing their valuable time to this research. Also, we thank Shannon Ryan for his contributions to the early stages of this study.

Contributors LM wrote the first draft. LM, WT, WH, LEN, MA, KA, SB, CD, OD, EE, JH, FJ-B, BK, DOL, ALK, HL, TM, PM, MN, AN, SO, CO-Z, CO, RS, SY, AH, AG, HI and $\mathrm{JE}$ codesigned the study and developed data collection instruments. All authors reviewed and approved the final version. 
Funding This work is supported by an award/grant from The Ontario HIV Treatment Network (OHTN).This study was supported by the Canadian Institutes of Health Research through an Operating Grant in the HIV/AIDS Community Based Research (CBR) Programme.

Competing interests None declared.

Patient and public involvement Patients and/or the public were involved in the design, or conduct, or reporting, or dissemination plans of this research. Refer to the Methods section for further details.

Patient consent for publication Not required.

Provenance and peer review Not commissioned; externally peer reviewed.

Open access This is an open access article distributed in accordance with the Creative Commons Attribution Non Commercial (CC BY-NC 4.0) license, which permits others to distribute, remix, adapt, build upon this work non-commercially, and license their derivative works on different terms, provided the original work is properly cited, appropriate credit is given, any changes made indicated, and the use is non-commercial. See: http://creativecommons.org/licenses/by-nc/4.0/.

ORCID iDs

Lawrence Mbuagbaw http://orcid.org/0000-0001-5855-5461

Daeria 0 Lawson http://orcid.org/0000-0002-6487-3367

\section{REFERENCES}

1 OACHA. Hiv/Aids strategy to 2026. secondary HIV/AIDS strategy to 2026, 2016. Available: https://bit.ly/2IPrA7E

2 OHTN. African, Caribbean and black communities. secondary African, Caribbean and black communities, 2018. Available: http:// www.ohtn.on.ca/research-portals/priority-populations/africancaribbean-and-black-communities/

3 Bourgeois AC, Edmunds M, Awan A, et al. Hiv in CanadaSurveillance report, 2016. Can Commun Dis Rep 2017;43:248-56.

4 Haddad N, Li JS, Totten S, et al. Hiv in Canada-Surveillance report, 2017. Can Commun Dis Rep 2018;44:324-32.

5 ACCHO. Ontario HIV/AIDS strategy for African, Caribbean and black communities 2013-2018. secondary Ontario HIV/AIDS strategy for African, Caribbean and black communities 2013-2018 2013. Available: http://www.accho.ca/Portals/3/documents/En_Avant_ Summary Report Final Feb2016 EN.pdf

6 Kerr J, Northington T, Sockdjou T, et al. Perceived neighborhood quality and HIV-related stigma among African Diasporic youth; results from the African, Caribbean, and black youth (ACBY) study. $J$ Health Care Poor Underserved 2018;29:651-63.

7 Gray K, Clazavara L, Tharao W, et al. The East African health study in Toronto (East): results from a survey of HIV and health-related behaviour, beliefs, attitudes, and knowledge. Toronto, Ontaro, Canada: HIV Social, Behavioural, and Epidemiological Studies Unit, Dalla Lana School of Public Health, University of Toronto, 2008.

8 Bekele T, Collins EJ, Maunder RG, et al. Childhood Adversities and physical and mental health outcomes in adults living with HIV: findings from the Ontario HIV treatment network cohort study. AIDS Res Treat 2018;2018:2187232
9 Harris GE. Practicing HIV/AIDS community-based research. AIDS Care 2006;18:731-8.

10 NHS. Census profile, 2016 census. secondary census profile, 2016 census 2018. Available: https://www12.statcan.gc.ca/censusrecensement/2016/dp-pd/prof/details/Page.cfm?Lang=E\&Geo1= PR\&Code1 $=01 \&$ Geo2 $=\&$ Code $2=\&$ Data $=$ Count $\&$ SearchText $=$ Canada\&SearchType $=$ Begins $\&$ SearchPR $=01 \& B 1=$ All $\&$ GeoLevel $=P R \&$ GeoCode $=01$

11 Canada S. Census program. secondary census program 2016. Available: https://www12.statcan.gc.ca/census-recensement/indexeng.cfm

12 Newcombe RG. Two-Sided confidence intervals for the single proportion: comparison of seven methods. Stat Med 1998;17:857-72.

13 Statistics Canada. Diversity of the black population in Canada: an overview, 2019.

14 Gray K, Calzavara L, Tharao W, et al. The East African health study in Toronto (East): results from a survey of HIV and healthrelated behavior, beliefs, attitudes, and knowledge. The HIV Social, Behavioural, and Epidemiological Studies Unit, University of Toronto, 2008.

15 Tharao W, Liu J, Husbands W, et al. HIV-related sexual behaviours among African-caribbean men in Toronto,Ontario. Secondary HIV-related sexual behaviours among African-caribbean men in Toronto,Ontario, 2013. Available: http://www.ohtn.on.ca/wp-content/ uploads//endgame/2/slides/Tharao-ACB-Men.pdf

16 Rourke SB, Gardner S, Burchell AN, et al. Cohort profile: the Ontario HIV treatment network cohort study (OCS). Int J Epidemiol 2013;42:402-11.

17 Loutfy M, de Pokomandy A, Kennedy VL, et al. Cohort profile: the Canadian HIV women's sexual and reproductive health cohort study (CHIWOS). PLoS One 2017;12:e0184708.

18 Anderson D, Burnham K. Model selection and multi-model inference. NY: Springer-Verlag, 2004: 63.

19 CHABAC. The African, Caribbean and black Canadian HIV/AIDS awareness day. secondary the African, Caribbean and black Canadian HIV/AIDS awareness day, 2018. Available: http://www. blackhivday.ca/awareness_day_fact_sheet_2018_EN_final.pdf

20 UNAIDS. Fast-Track strategy to end the AIDS epidemic by 2030. secondary fast-track strategy to end the AIDS epidemic by 2030 , 2018. Available: http://www.unaids.org/en/resources/campaigns/ World-AIDS-Day-Report-2014

21 Sanci LA, Sawyer SM, Weller PJ, et al. Youth health research ethics: time for a mature-minor clause? Med J Aust 2004;180:336-8.

22 Viner RM, Barker M. Young people's health: the need for action. BMJ 2005;330:901-3.

23 Rotermann M, Sex RM. Sex condoms and STDs among young people. Health Rep 2005;16:39.

24 Flicker S, Guta A. Ethical approaches to adolescent participation in sexual health research. J Adolesc Health 2008;42:3-10.

25 Gubrium A. Digital storytelling: an emergent method for health promotion research and practice. Health Promot Pract 2009;10:186-91.

26 Moffitt P, Vollman AR. Photovoice: picturing the health of Aboriginal women in a remote Northern community. Can J Nurs Res 2004;36:189-201. 